\title{
CARTOGRAPHIC MODELING OF LAND SUITABILITY FOR INDUSTRIAL DEVELOPMENT IN THE EGYPTIAN DESERT
}

\author{
H.A. EFFAT \& M.N. HEGAZY \\ National Authority for Remote Sensing and Space Sciences, Egypt.
}

\begin{abstract}
Land-use decisions and planning processes deal with large volumes of basic data where technical knowledge must be coordinated with the decision makers' views of society. This fact makes spatial planning a very complex process. This paper addresses a regional scale zoning issue through cartographic modeling using geographic information science through a case study. It utilizes a theoretical framework that can potentially assist planners in this regard, namely the multicriteria evaluation (MCE) theory. The paper demonstrates an approach that combines geographic information system with MCE techniques for the land-use decision support system on the strategic scale. A national geographic database was established for the desert land of Egypt. Criteria for industrial development of land including the land constraints and potential resources were identified based on selected objectives and strategy proposed by decision makers. Factors were ranked, scaled and assigned a relative importance weight. The constraints were masked out. Running the cartographic model produced the land suitability index for industrial development. The suitability index was further classified into five phases of suitability zones. The result is a zoning map for potential sites for residing industrial-based activities with varying classes of suitability. The applied methodology can provide what-if land-use scenarios based on the strategic objectives and their relative selective set of criteria.
\end{abstract}

Keywords: decision support systems, geographic database, geographic information system, land-use strategy, remote sensing, suitability, zoning map.

\subsection{The study region}

\section{INTRODUCTION}

The geographic location of Egypt lies between longitudes $22^{\circ}$ and $32^{\circ}$ north and between latitudes $24^{\circ}$ and $37^{\circ}$ east. The country is bordered by the Gaza Strip $11 \mathrm{~km}$, Israel $255 \mathrm{~km}$, Libya $1,150 \mathrm{~km}$ and Sudan 1,273 km. The total area of Egypt amounts to 1,001,450 km². Land occupies 995,450 km² and the water bodies occupy $6,000 \mathrm{~km}^{2}$. Deserts occupy almost $96 \%$ of the Egyptian land cover. A vast majority of its 78 million population in 2006 was mainly concentrated in the Nile Valley and the Delta as well as in the coastal zone along the Mediterranean Sea. Inhabited area represents only $4 \%$ of the total territory. Rich in unexplored potentials, the vast desert zones are being joined and accessed by the development corridors linking the Egyptian cities and towns.

\subsection{Objectives of the study}

The Egyptian government adopts a strategy for future urban development and population redistribution outside the Nile Delta and Valley through exploring the potentials and resources of the vast desert lands. Therefore, the main objective of this study is to contribute to the efforts of exploring the desert resources and their suitability to locating zones for industrial development.

Another objective of this study is to explore the potentials of remotely sensed data and geographic information sciences in linking the gap between geoscience conceptual theories and land-use decisions 
in the field of regional planning. The study attempts to apply the multicriteria evaluation (MCE) theory in a geographic information system (GIS) environment for producing a suitability index map for locating new industrial zones in the Egyptian deserts.

\subsection{Literature review}

Decision-making problem arises when there is a difference between the present state and the desirable state, the need for change is identified and there are at least two courses of action possible. Preferably, the best alternative should be selected. Solving such a problem can be managed by dividing it into smaller, easier to handle parts, analyze each part separately and integrate all the analysis results into one meaningful proposal [1]. This fact applies to land-use and zoning decisions. Belka [1] and Heywood [2] explain that cartographic modeling is an example of an advanced method of GIS analysis. It consists of data pre-processing, graphical representation of the process of modeling as a flowchart and execution of the model using GIS operations. Cartographic modeling applies map algebra tools together with other basic analysis operations in GIS. Multicriteria decision making (MCDM) is a term that includes multiple attribute decision making (MADM) and multiple objective decision making (MODM). MADM is applied when a choice out of a set of discrete actions is to be made. MADM is often referred as multicriteria analysis (MCA) or MCE. The main objective of MCDM is 'to assist the decision maker in selecting the "best" alternative from the number of feasible choice alternatives under the presence of multiple [decision] criteria and diverse criterion priorities'. Every MCDM technique has common procedure steps, which are called a general model Jankowski [3]. Despite the close relationship between the geographic information science and landuse studies, there has been little constructive dialogue on the relationship between MCDM and land-use analysis and practical applications. Spatial MCDM refers to the use of MCA to spatial decision problems Voogd [4]. MCA is a family of operations research tools that have experienced very successful applications in different domains since 1960. It has been coupled with GIS since the early 1990s for an enhanced decision making. Remotely sensed data together with GIS have been recently used in land-use decision analysis. Cartographic modeling and suitability mapping of land in accordance to its potentials and constraints using MCE techniques have been broadly applied. Eastman [5] explains that in order to define the suitability of an area for a specific practice, several criteria need to be evaluated. MCE has been developed to improve spatial decision making when a set of alternatives need to be evaluated on the basis of conflicting and incommensurate criteria. It is an effective decision-making tool for complex issues that use both qualitative and quantitative information. It has been utilized around the world for land suitability modeling and is concerned with how to combine the information from several criteria to form a single composite index of evaluation. A criterion may be a factor providing suitability of phenomenon of continuous measure or may be a constraint to limit the alternatives under consideration. The MCE in its weighted linear combination method introduces a soft or 'fuzzy' concept of suitability in standardizing criteria. It is scaled to a particular common range where suitable and unsuitable areas are continuous measures. The aggregation method uses weighted linear combination, which retains the variability of continuous criteria and allows criteria to trade off with each other. Sahoo et al. [6] explains that MCE is primarily concerned with how to combine the information from several criteria to form a single index of evaluation. As the criteria are measured at different scales, they are standardized and transformed such that all factor maps are positively correlated with suitability [7]. Belka [1] and Jankowski [3] explain that the weighted summation allows for evaluation and ordering of all alternatives based on the criteria preferences by decision makers. Example of raster based MCE is given by Rapaport and Snickars [8] and Grossardt et al. [9]. 


\subsection{Data sets}

The primary datasets used were obtained from various national and international sources. The land cover map was obtained from the Food and Agriculture Organization (FAO) [10]. The hydro-geological maps were obtained from the National Water Resources Center Research Institute for Groundwater [11]. Current and future protectorates maps from the Egyptian Environmental Affairs Agency (EEAA) [12]. The topographic base map was obtained from the Military Survey Department [13]. Mines and quarries map was obtained from the Egyptian Center of Building Researches [14]. The geological map was obtained from the Egyptian General Petroleum Corporation, CONOCO [15]. Above mentioned datasets were obtained in analogue form.

\section{METHODOLOGY}

Cartographic modeling is an example of an advanced method of GIS analysis. In general terms, a model is a representation of reality; it represents only those factors that are important to the work flow and creates a simplified, manageable view of the real world. Different solutions can be obtained by modifying parameter values in the model to explore 'what-if' scenarios and obtain different solutions, such as applying the same model to different geographic locations by changing the input data [16]. A cartographic model is a 'methodology for structuring a GIS analysis scheme' [2]. MCDM is a term that includes MADM and MODM. MADM is applied when a choice out of a set of discrete actions is to be made. In MODM, it is assumed that the best solution can be found anywhere in the feasible alternatives space, and therefore is perceived as continuous decision problem. MADM is often referred as MCA or MCE. Instead, MODM is more close to Pareto optimum searching with use of mathematical programming techniques [1, 3, 17].

The acquired maps were on-screen digitized, rectified and saved as feature classes. A geographic database was created. The geographic database and the thematic layers were projected to the Universal Transverse Marketer, UTM WGS84. These vector pre-processed data (thematic layers) were converted into raster in order to prepare for further analysis. In raster format, the GIS environment is set for the extent of study area and if necessary a mask is set for constraint zones, it also avoids the topological errors common in vector analysis. Data layers excluding linear features were converted to raster format. Using ESRI Spatial Analyst, the raster calculator and distance functions were used [16]. A flowchart was designed for the model (Fig. 1).

\subsection{Defining and mapping the criteria maps}

MCE terminology introduces the term evaluation criteria, which contains both objectives and attributes. Objectives describe the purpose of a change and the attributes define the way the change will be measured. However, the objectives are further formulated by a set of criteria. If attributes can have numerical values, they can be referred as scores [1]. Selecting a proper set of evaluation criteria can be done by means of literature study, analytical studies or survey of opinions. Literature can be found with some authors providing literature review of criteria evaluation to a specific spatial decision problem. Governmental agencies and governmental publications can provide guidelines for selection of evaluation criteria. Another method is to recognize objectives from governmental or other documents and review relevant literature to identify attributes associated with every objective. Opinions' survey is aimed at people affected by decision or a group of experts, where several formalized techniques exist $[3,6]$.

Identifying the land's potentials and constraints for zoning industrial sites in the desert was done through intensive literature and expert consultations. The criteria set included constraints 


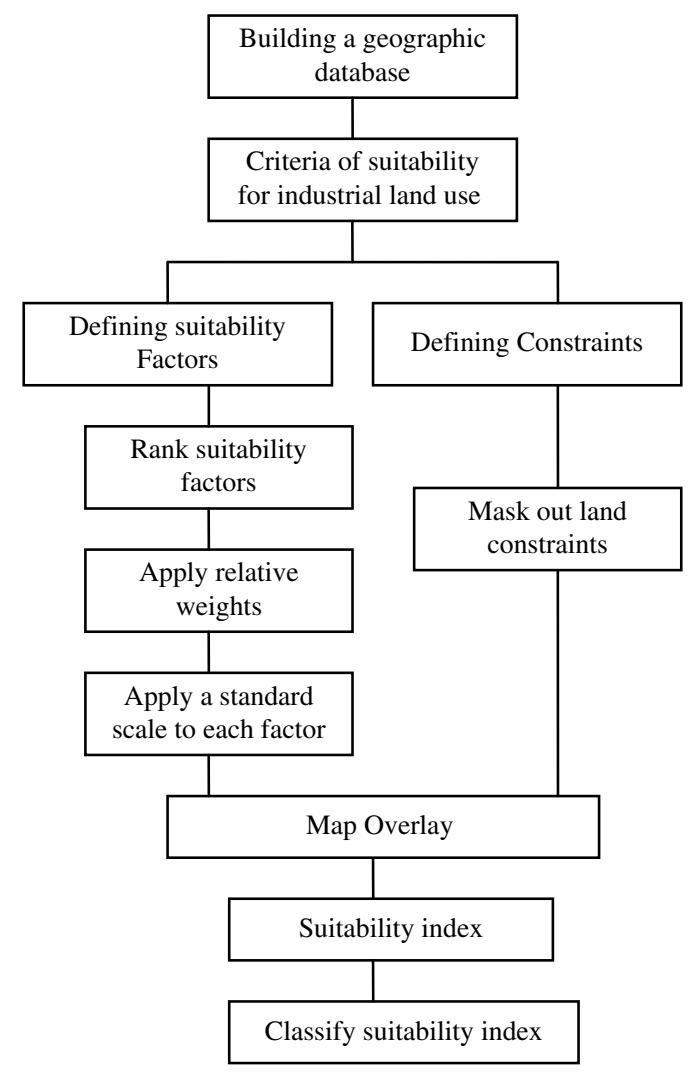

Figure 1: Conceptual design for deriving the land suitability index.

thematic maps that consist mainly of hazardous zones such as rock-collapse risk zones and sand dunes as well as protected zones such as cultivated lands, natural vegetation and protected areas. The criteria also included factors thematic maps such as recourse maps, mines and quarries, water and power supply, rock type and distance maps. The selected criteria sets are explained in the following section.

\subsection{Preparation of the criteria maps}

Criterion maps are produced as an output of the criteria identification phase. These maps are the input for the MCE cartographic model. The process includes data acquisition, reformatting, georeferencing, compiling and documenting relevant data stored in graphical and tabular form, which is manipulated and analyzed to obtain desired information. For this study, a base map for the study area was created and the thematic layers were exported to a geographic database and used to produce several criterion maps. The selected criteria maps used as input for the analysis is described in this section (Fig. 2). As the movement on the land does not happen in all directions but on strictly defined networks (such as roads, railways and utility lines), the use of consecutive buffer zones was applied using the straight distance function in ArcGIS software (Fig. 2). 


\subsubsection{Mines and quarries}

The availability of mines or quarries is an essential factor for industrial activities in the Egyptian desert, which is rich in building materials and a variety of mining resources. The mines and quarry sites were mapped and used as factor maps.

\subsubsection{Water resources}

Due to water scarcity, the availability of surface or underground water resource is one of the essential factors for identifying new industrial zones. Both surface and underground water resources were scanned, digitized and used as factor maps.

\subsubsection{Power supply}

The proximity of the site to a power supply such as high electric lines or power stations is an essential economic factor for locating an industrial activity. The high electric lines and power stations were mapped from the topographic map, saved as a feature class and used as factor maps.

\subsubsection{Rock type map}

As the study area is mostly a desert environment, therefore agriculture land is given a first priority compared to industrial activity. Due to the absence of a soil map for some desert zones, the rock type was mapped from the geological map, saved as a feature class and used as a guide in order to avoid soils that are favorable to future cultivation and land reclamation.

\subsubsection{Proximity to shorelines}

The proximity to shorelines is an economic factor for industrial development. Shorelines can habitat ports and harbors that promote exchange of goods, raw materials and trade. Therefore, the distance to a shoreline was considered as a factor. The shoreline was mapped, saved as a feature class and the distance to shorelines was used as a factor map.

\subsubsection{Proximity to cities}

Due to the vast desert areas, the proximity of an industrial site to an urban settlement is an essential economic factor as urban areas provide the manpower resource in addition to the basic services. The cities boundaries were digitized from the topographic map, a distance function was applied and used as a factor map.

\subsubsection{Proximity to roads}

As roads are the main arteries for any development site, providing accessibility and linking its remote areas, it is a main factor in the selection of industrial zones. Roads were digitized from the topographic map. A distance function was applied to the road layer and used as a factor map.

\subsubsection{Cultivated lands}

The cultivated land in Egypt is mainly concentrated in Nile Delta and Valley in addition to some coastal belts and few desert oases. The arable land is legally protected from land-use changes. The cultivated lands of Egypt were derived from the FAO Africover project data available online [10]. The cultivated lands layer was downloaded, updated using a recent version of Landsat ETM+ image and used as a constraint layer.

\subsubsection{Natural vegetation}

The desert natural vegetation in Egypt has environmental and economic values. Therefore, it was an objective of the study to help preserve natural vegetation zones. FAO land cover was used to extract the natural vegetation layer which was used as a constraint. 


\subsubsection{Sand dunes}

Sand dunes are one of the obstacles for locating new projects in Egypt. As dunes are affected by wind, sand dunes' movement may cause burial of roads, constructions and dwellings. It was considered as one of the constraints to locating new industrial zones. FAO dataset was used to extract the sand dunes layer from the land cover. The dunes layer was exported as a feature class in the geodatabase and was used as a constraint.

\subsubsection{Protected areas}

Natural protectorates have environmental values for preservation of scenic sites, flora and fauna. National parks were considered a constraint to locating new industrial sites. The protected areas map was obtained from the EEAA [12], converted to a digital form, rectified, projected and exported to the geographic database as a feature class and used as a constraint map.

\subsection{Criteria weighting and standardization}

Criterion weights are usually determined in the consultation process with decision makers, which results in ratio values being assigned to each criterion map. They reflect the relative preference of one criterion over another. The straight rank sum weighting of criteria has been described by Malczewski [17], McHarg [18], Jankowski and Richard [19], Malczewski [20] and Bernhardsen [21]. The method was selected for this study due to its simplicity that promotes its applicability by the decision makers. In straight ranking, factors are ranked in order, from most to least relative important in the selected criteria list. After the ranks were established, weights were assigned to the factors, a table was constructed to weight every criterion and then the total score for each alternative was calculated [see Table 1 and eqn (1)].

$$
w_{j}=\left(n-r_{j}+1\right) / \operatorname{SUM}\left(n-r_{k}+1\right)
$$

where $w_{j}$ is the normalized weight for the $j$ th factor, $n$ is the number of factors under consideration, $r_{j}$ is the rank position of the factor. $r_{k}$ is the factor number.

As long as the criteria and the criterion maps have different scales of measurement, they cannot be compared by their raw scores. In order to allow comparability, which is essential to MCE, the

Table 1: Criteria ranking and applying relative weights for suitability.

\begin{tabular}{llcc}
\hline Rank & Criteria (layer) & $\begin{array}{c}\text { Weight } \\
\left(n-r_{j}+1\right)\end{array}$ & $\begin{array}{c}\text { Normalized weight } \\
\left(n-r_{j}+1\right) / \mathrm{SUM}\left(n-r_{k}+1\right)\end{array}$ \\
\hline 1 & Mines & 8 & $17.5 \%$ \\
1 & Quarries & 8 & $17.5 \%$ \\
2 & Lithology & 7 & $15.3 \%$ \\
3 & Power supply (layers) & 6 & $13 \%$ \\
5 & Near settlements & 4 & $8.7 \%$ \\
4 & Road network & 5 & $10.8 \%$ \\
6 & Shorelines & 3 & $6.4 \%$ \\
4 & Water resources (layers) & 5 & $10.8 \%$ \\
26 & Sum & 46 & $100 \%$ \\
\hline
\end{tabular}


criterion maps should be standardized. Both linear and nonlinear standardization procedures exist. If it concerns deterministic maps, where each alternative is related to a single value, linear scale transformation methods are most frequently used. Standardization methods, including probabilistic and fuzzy relationships, are described thoroughly by Jankowski [3] and Bernhardsen [21]. Thus, normalization of the factor maps to a common suitability scale was done to allow for map overlay functions.

\subsection{Weighted overlay}

Raster overlaying is known as scalar overlaying because it uses mathematical operations such as addition, subtraction, multiplication and division. It is described as map algebra; the result is a raster layer $[1,3]$. The standardized and weighted factor maps were overlaid using ArcGIS9 spatial analyst software [16]. The resultant factors fuzzy index maps were multiplied by the constraint map to mask out the restricted zones. The average suitability score is calculated as shown in eqn (2):

$$
\bar{S}=\frac{\sum_{i=1}^{n}\left(W_{i} \times S_{i j}\right)}{\sum_{i}^{n} W_{i}}
$$

where $\bar{S}$ is the weighted average suitability score, $W_{i}$ is weight for $i$ th map and $S_{i j}$ is score for $j$ th class of the $i$ th map. The assigned importance weight $W_{i}$ depends on the variable significance with respect to the land suitability $\bar{S}$ for a studied activity.

\subsection{Development corridors - suitability scenarios}

A $40 \mathrm{~km}$ buffer zone was created around the development corridors to limit the analysis within the corridors' vicinity. Such buffer was used to clip the resultant suitability index map, which was then classified into 11 classes using the natural breaks method. The five highest values were selected and used to propose a scenario of five phases for potential sites for locating industrial zones in the desert (Fig. 4).

\section{RESULTS AND DISCUSSIONS}

The suitability factors maps provided a new vision for the spatial distributions of essential parameters for land-use decision making. Standardized classes of aquifer units are shown in Fig. 2a. Such map reveals the distributions of ground water in the Egyptian desert. Extensive aquifers are present in the Western Desert and central zones in Sinai Peninsula. Similarly, the standardized map for rock type (shown in Fig. 2b) identifies the most suitable rock units. Such units exist in the Western Desert as well as the Eastern Desert and in the middle of Sinai Peninsula. The distance to cities map provides a distance scale for the spatial distribution of cities in Egypt through consecutive buffer zones (Fig. 2c). The nearest buffers are the most suitable locations for zoning industrial cities within a buffer distance of $40 \mathrm{~km}$ from cities. Distance to power supply provided a vision to the spatial distribution of the service in the desert zones. Highest suitability score was assigned to the buffer zone of $44 \mathrm{~km}$ distance (Fig. 2d). Distance to mines resource map reflect zones within mines vicinity, mainly existing in the Eastern Desert and parallel to the Red Sea shoreline. The buffer zone of $52 \mathrm{~km}$ from mines was given the 

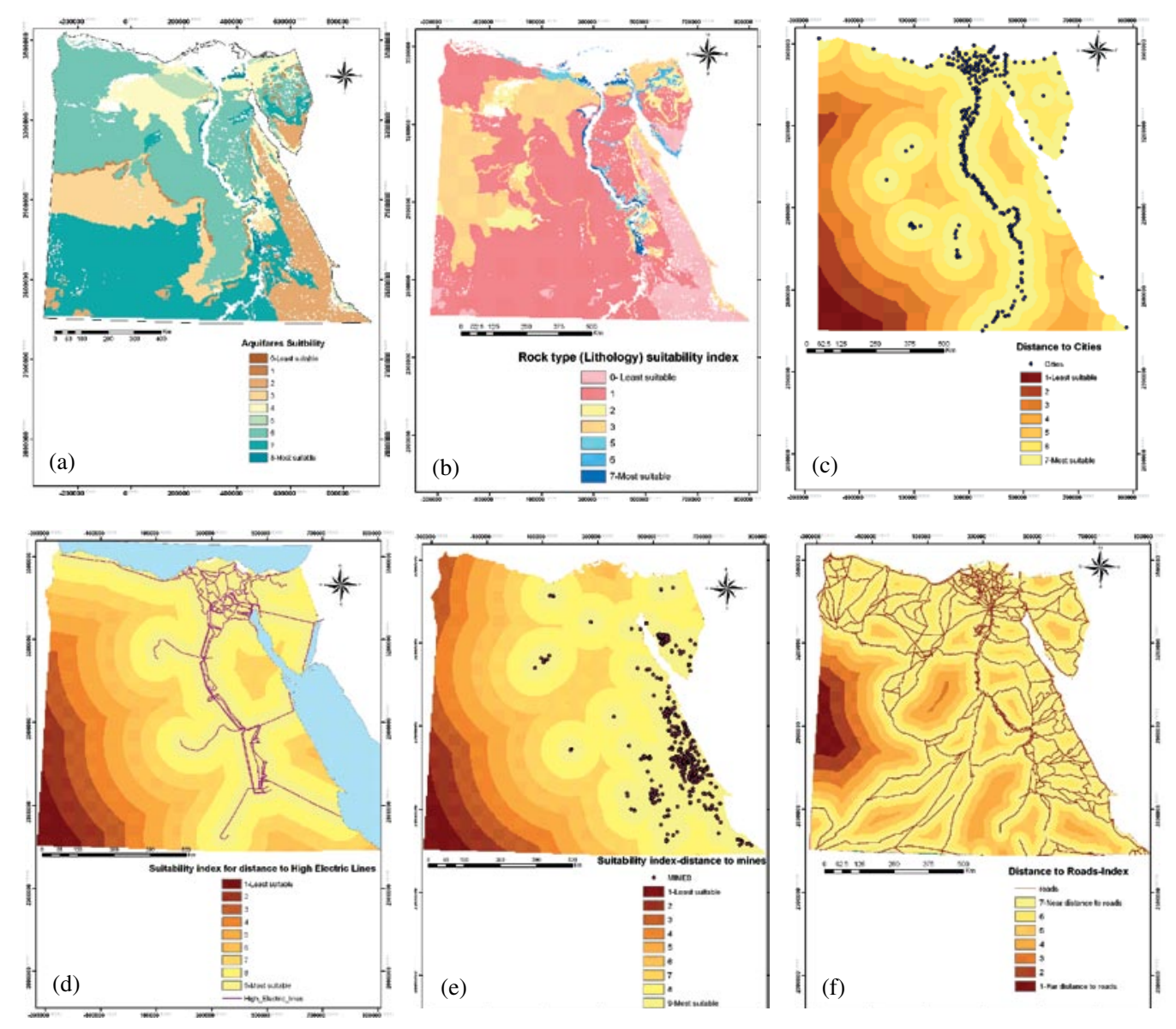

Figure 2: Factor maps: (a) aquifer units' suitability, (b) rock type (lithology) suitability map, (c) distance to cities, (d) distance to power supply, (e) distance to mines and (f) distance to roads.

highest suitability score (Fig. 2e). Distance to roads and accessibility map revealed the most suitable zones within $13 \mathrm{~km}$ around a road (Fig. 2f).

Running the MCE model resulted in the suitability index for the spatial distribution of the most favorable industrial development zones in the Egyptian territory based on the selected set of criteria. Highest suitability scores that comply with the selected criteria set were recorded in Sinai Peninsula, the Eastern Desert and along the Nile Valley. Such zones reflect the potential sites for site selection of new industrial zones in the desert.

Classification of the suitability index map to a range of suitability values facilitated the comparison of the various zones in the desert (Fig. 3). From the suitability map, the authors outlined a strategy for industrial development zones. Spatial distribution of highest suitability values depicted by the highest value (class 11) was selected for proposed priority phases of potential sites for industrial development. Accordingly, class 10 can be assigned for the second phase, and eventually an industrial zoning strategy of several phases was composed (Fig. 4) based on the resultant suitability map. 


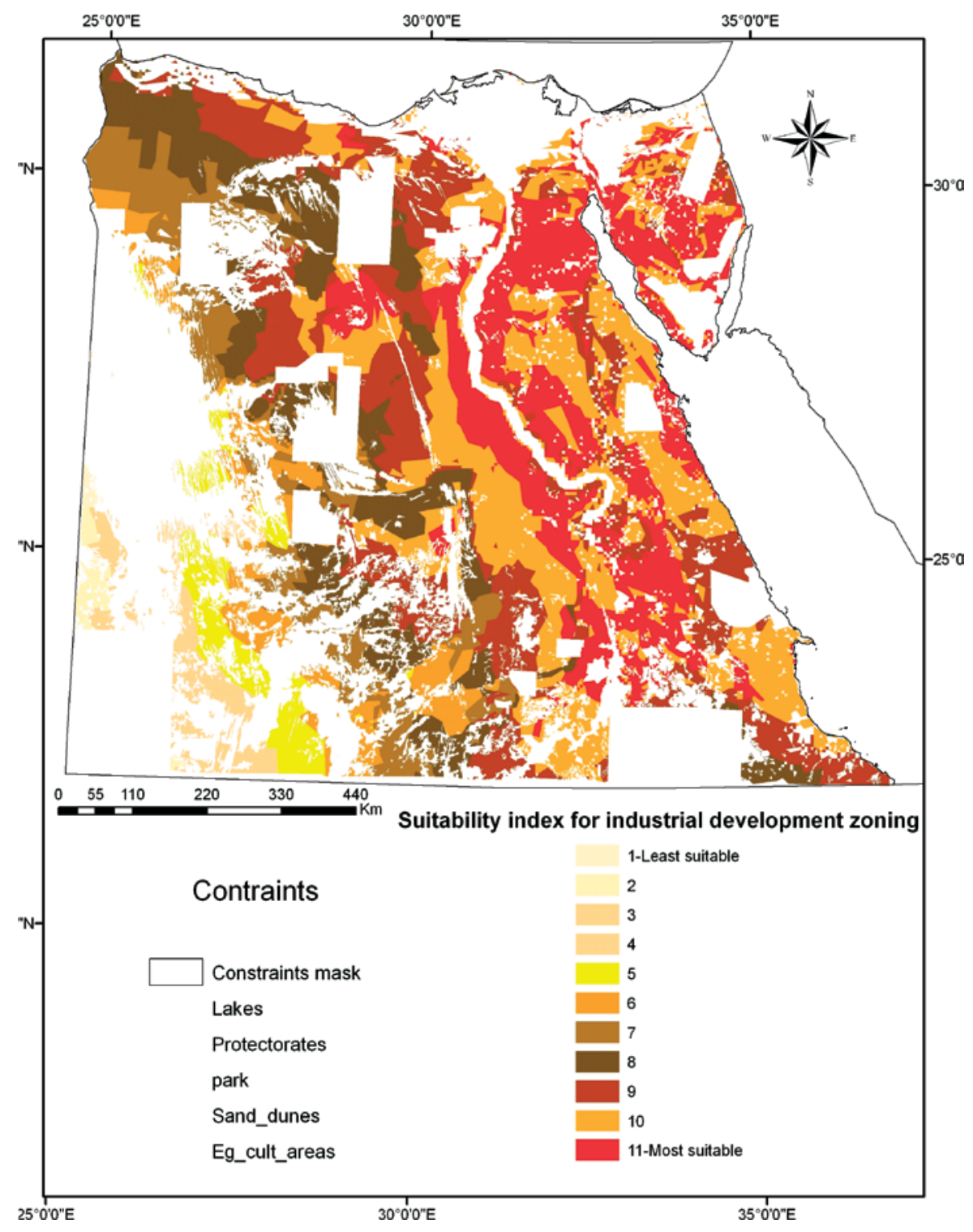

Figure 3: Suitability map for locating industrial zones in the Egyptian desert.

\section{CONCLUSION AND RESEARCH APPLICABILITY}

This study focuses on the necessity of integrating land resources, potentials and constraints in the land-use decision strategies as an attempt to achieving sustainable planning in Egypt. The use of remotely sensed data, GIS databases and MCE has proved to be a useful tool for achieving the above goal.

The study used analytical methods that include studying spatial relations such as distance functions as well as employment of the qualitative attributes such as aquifers and rock types. However, 

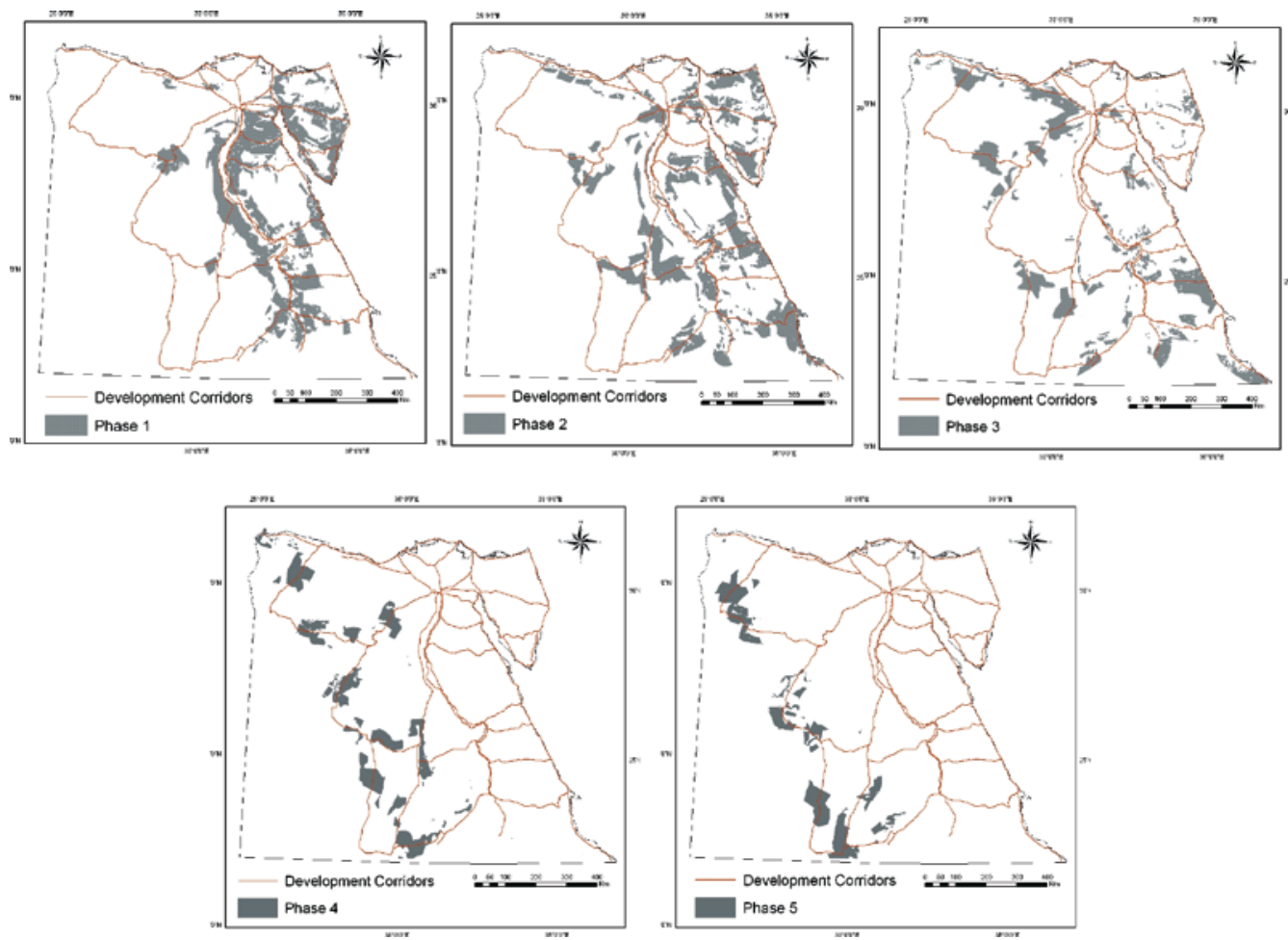

Figure 4: The proposed strategy for residing industrial development around the development corridors.

In reality, the interconnection of the anthropogenic factors and the physical environment forms a more complex system. The reason is that the spatial elements change by the anthropogenic factor. The construction of a new development corridor or the reclamation of a new protectorate area can change the model result. Thus, this kind of models requires regular updates of the database. Data availability is important for designing of the analysis functions and process. However, flexibility of GIS-based method makes it easy to incorporate additional data sources; the presented evaluation criteria realize the preservation policy for the land constraints and sensitive zones such as natural and cultivated lands in addition to non-favorable sites such as sand dunes. Their point is to illustrate what kind of criteria should be taken into consideration in suitability analysis; also, it is possible for additional goals to be set for zoning of industrial sites. The parameter values of the input data set can be easily modified to provide different 'what-if scenarios'. This is quite a helpful tool for decision makers in land-use planning as the same model can be applied to different geographic areas by changing the input data. The applied technique bridges the gap to a multidisciplinary approach for land-use planning on the different levels. Applying this technique on regional coarse scales provides indicator maps that, despite of their need to more detailed analysis, can be used as guidelines for zoning plans and land-use strategies. These maps point out promising zones and hotspots for specific land-use decisions. This technique also provides unlimited possibilities to create land-use scenarios based on a selected set of criteria. The selective criteria should be a reflection of the decision makers' objectives and priorities. Various scenarios can be produced by altering the input parameters, ranks and 
relative weights through which 'what-if' scenario outputs are made possible. This technique can be time and cost saving for land-use decision makers.

The resultant suitability map can be used as an indicator and guideline by urban planners to make sustainable land-use decisions on the broad regional scale. The methodology adopted in this study can be used by the regional land-use planners. It is recommended that the land-use decision makers adopt the MCE technique in a GIS environment. It is also recommended that further studies be conducted to apply this technique in the various land-use planning levels. This integrated approach is believed to overcome the shortcomings of the current planning practice especially in developing countries, owing mainly to the lack of integrated vision and evaluative scenarios in the land-use planning sector.

\section{ACKNOWLEDGEMENT}

This paper is part of a research project entitled 'The Strategy of Optimum Use of the Development Corridors in Egypt', conducted at the Egyptian National Authority for Remote Sensing and Space Sciences (NARSS). The authors wish to thank Prof. Ayman El Desouky, chairman of NARSS, for his continued support, follow-up and scientific advice which are deeply appreciated by the authors.

\section{REFERENCES}

[1] Belka, K.M., Multicriteria analysis and GIS application in the selection of sustainable motorway corridor. Master's thesis submitted to Linköpings universitet Institutionen för datavetenskap. ISRN-LIU-IDA-D20--05/019-SE, 2005

[2] Heywood, I., Cornelius, S. \& Carver, S., An Introduction to Geographical Information Systems, Prentice Hall: Harlow, 2002.

[3] Jankowski, P., Integrating geographical information systems and multiple criteria decision- making methods. International Journal of Geographical Information Systems, 9(3), pp. 251-273, 1995. doi:10.1080/02693799508902036

[4] Voogd, H., Multicriteria Evaluation for Urban and Regional Planning, Pion: London, 1983.

[5] Eastman, E.R.J., IDRISI 32. Guide to GIS Image Processing, volume 2, Clark Lab, Clark University: Worcester, MA, USA, 1999.

[6] Sahoo, N.R., Jothimani, P. \& Tripathy, G.K., Multi-criteria analysis in GIS environment for natural resource development. A case Study on Gold Exploration. Online publications cited from GIS development.net, http://www.gisdevelopment.net/magazine/gisdev/2000/may/gise. shtml, 2000.

[7] Saaty, T.L., The Analytic Hierarchy Process, McGraw Hill: New York, 1980.

[8] Rapaport, E. \& Snickars, F., Integration of environmental risk into the road location analysis: A GIS based case study to minimize environmental impacts, building costs, and traveling time. Not revised version. http://stratema.sgis.net/cupum/pdf/E8.pdf, May 20, 2005.

[9] Grossardt, T., Bailey, K. \& Brumm, J., Analytic minimum impedance surface: geographic information system-based corridor planning methodology. Transportation Research Record, No. 1768 , pp. 224-232, 2001. doi:10.3141/1768-26

[10] Food and Agriculture Organization of the United Nations (FAO). Egypt Multipurpose Land Cover Database (Africover), http://africover.org, 2002.

[11] Research Institute for Groundwater (RIGW), National Water Research Center (NWRC). The hydro-geological map of Egypt, scale 1:200,000, 1999.

[12] Ministry of state for the Environment, Egyptian Environmental Affairs Agency (EEAA), Department of Nature Conservation, National Biodiversity Unit, Egypt: National Strategy and Action Plan for Biodiversity Conservation, 1998. 
[13] Military Survey Department, The topographic map of Egypt, 1995.

[14] Center of Housing and Building Researches, Ministry of Housing, Utilities and Urban Development, Egypt, Mines and quarry map of Egypt, 2007.

[15] Egyptian General Petroleum Corporation, CONOCO-Coral, The geological map of Egypt, Scale 1:500,000, EGPC, Cairo, 1987.

[16] ESRI, ArcGIS9, Working with Spatial Analyst, ESRI: New York, USA, 2001-2002.

[17] Malczewski, J., GIS and Multicriteria Decision Analysis. John Wiley \& Sons: New York, 1999.

[18] McHarg, I.L., Design with Nature, John Wiley \& Sons: Garden City, New York, 1969.

[19] Jankowski, P. \& Richard, L., Integration of GIS-based suitability analysis and multicriteria evaluation in a spatial decision support system for route selection. Environment and Planning B: Planning and Design, 21, pp. 323-340, 1994. doi:10.1068/b210323

[20] Malczewski, J., GIS-based land-use suitability analysis: a critical overview. Progress in Planning, 62(1), pp. 3-65, 2004. doi:10.1016/j.progress.2003.09.002

[21] Bernhardsen, T., Geographic Information Systems: An Introduction, 3rd edn, Asplan Viak: Norway, 2002. 